\title{
NEW MATERIALS FOR CONSTRUCTION WITH 3D PRINTERS, COMPARATIVE STUDY
}

\author{
M. Valiente López ${ }^{1}$, S. Moyano Sanz ${ }^{1}$ M.C. Sanz Contreras ${ }^{1}$ \\ ${ }^{1}$ Universidad Politécnica de Madrid (SPAIN)
}

\begin{abstract}
In the Building Engineering School, POLYTECHNIC UNIVERSITY OF MADRID we are studying new materials for the construction made by 3D printers, and we are going to see the importance of 3D printers in our educational experience. We will see the benefits of using this new ways of presenting projects.

As an example we will see a comparative study of materials, used in the production of the architectural objects made with 3D printers, is also presented. We will analyse the new technologies of 3D printers and their use in the construction of buildings. The printers in 3 Dimensions are the real technological revolution.

We propose a series of objectives to carry out this investigation. The main objective is to see why $3 \mathrm{D}$ printers are the key of our studies. We will study some examples of the uses of the 3D printers, in education. For instance, we will design a functional part, suitable for building construction in modules, to improve the features of existing bricks, and to provide all the advantages of new 3D printing technologies, in the field of building. Once the pieces are designed and printed, the laboratory tests are performed for both bricks and plastics, and the results are compared. The specific objectives, in order to design these pieces, are addressed to solve some problems.
\end{abstract}

Our methodology presents different ways of solving 3D printing problems, in education. There are different methods to avoid warping in our 3D printing parts, and there are as many solutions. It is a matter of finding the best one which suits our working method.

Our conclusions will be how different works in this area have been resolved, and why this is important in Building Engineering education.

For example, we can see that with this new execution system, we can print on-site every piece required at any time by using the new P.M.T.P designing methodology, (Printed Thermoplastic Modular Piece) and the importance of these methods in architectural education.

With this information we can propose a series of hypotheses based on the data used as the basis for initiating an investigation.

Keywords: Architectural Education, Edification, educative innovation in the university, new technologies

\section{INTRODUCTION}

This research is the result of work carried out by the PIE-DIBARQ Group of Educational Innovation ETSEM-UPM during the 2016-2017 courses in its effort to implement a methodology adapted to the new requirements of European Convergence in Higher Education through the use of new technologies and the introduction to them for the students.

Nowadays we are not only teaching conventional techniques, but they're trying, at least experimentally, to show each student more innovative ways in Architectural Representation. This is the case of the use of computers, and the new language BIM. We are not only referring to the computer-assisted instruction, where the teacher is developing several experimental units as fixing the theoretical concepts taught, but also to the use and knowledge of the computer as an element used by the professional as a graphic expression of their ideas, or studies.

Although the concept of $3 \mathrm{D}$ printer has its origin in the 80 's it is now taking more and more strength, and it is already starting to be used in many industries. The future of 3D printers is promising and from 2014 we begun to be more familiar with them and for sure we will get better printer with a lower prices. 
The 3D printer is considered by the European Space Agency (ESA) as a pioneering invention of the Third Industrial Revolution, as the steam engine and the internal combustion engine were once. The ability to print anything we have in our computer modelling before is a real change in our conception of production, being classified by experts as disruptive technology more powerful than the Internet itself. If it was possible to print parts for spaceships, food and even human organs, the range of possibilities expands the conception of a giant 3D printer in 24 hours can build a house of more than 200 square meters.

Although this is the future of printing the truth it is that when one starts to learn seriously about a 3D printer, discovers with some frustration that the information accessible is rather fanciful. Much is written about the potential of these machines, and we found images of beautiful sculptures of impossible shapes, jewellery or accessories that seem to be taken from a workshop of professional jewellery.

In this paper we will see the problems and resolution of the 3D printing in Architecture.

The first 3D printer, released in 1984, by Charles Hull co-founder of the American company 3D Systems. Since then, there have been numerous companies that have reinvented the printer and its way of using it, to the point that nowadays, we can print tools, food, jewelry, human organs, etc. In fact, there are self-replicating printers, where Dr. Adrian Bowyer, of the University of Bath, initiates an investigation to build printers that can print themselves, in almost all its components, we speak then, of the reproduction of the $3 \mathrm{~d}$ printers. [5]

There are numerous techniques of $3 \mathrm{D}$ printing, in our case, we will use printing by adding material layer by layer or by manufacturing by cast filament deposition (FFD).

This technique is the most daily. It is based on a printing bed in which the piece is printed, a filament coil that serves as printing material and an extrusion head, also called an extruder. The filament is sucked and fused by the extruder of the 3D printer, which deposits the material accurately layer by layer on the printing bed. [6]

Currently, there are many types of filament used in these printers, for our research, we will name those that, a priori, we could use to make our pieces. [7]

- $\quad$ PLA (Lactic Polyacid).

- It is a biodegradable, ecological and renewable material, comes from organic matter such as corn or wheat, becomes feeble at $60^{\circ} \mathrm{C}$, is very fragile and sensitive to moisture.

For these reasons, it is discarded for the elaboration of the pieces of this investigation.

- $\quad$ ABS (Acrylonitrile Butadiene Styrene).

- $\quad$ This material, comes from petroleum, is very stable, tenacious, has high machining capacity, resistant to chemical attacks and impacts.

At first, the possibility of using this material was considered, but before the appearance of warping, due to the characteristics of the piece, we opted to look for other alternatives.

- $\quad$ PET (Polyethylene terephthalate).

- $\quad$ This material is used for food, it is a polyester, has high transparency, even in colored filaments, good chemical, thermal and impact resistance, impermeable, toxic, non-biodegradable and becomes weak from $70^{\circ} \mathrm{C}$.

For these reasons, it is discarded for the elaboration of the pieces of this investigation.

- $\quad$ HIPS (High Impact Polystyrene).

- It is a polymer mixed with repetitive structures of styrene and butadiene, generating a high capacity of resistance to impacts, high resistance, recyclable, thermal stability, high machining capacity, resistant to water, thermal insulation, begins to deform from $95^{\circ} \mathrm{C}$.

For these reasons, this material is chosen for the elaboration of the pieces of this investigation.

- $\quad$ Carbon fiber.

- Very resistant and ultra-light material, great adhesion and reinforcement between layers, good thermal insulation, fibrous finish, impact resistant, very high printing temperatures, very abrasive. 
For these reasons, it is discarded for the elaboration of the pieces of this investigation.

In addition, we will need a joining material between pieces, with the following characteristics:

- $\quad$ Flexible (thermoplastic elastomer or TPE).

- Known by the name of FILAFLEX, it is flexible by the combination of thermoplastic and elastomer, cushioning impacts, resistant to breakage by fatigue, recyclability, stretch capacity and recovery.

Although HIPS is used as a supporting element or support material for the printing of other objects, we believe that the combination of this with the FILAFLEX, can provide the characteristics that we need for the manufacture of the pieces of this research.

\section{OBJECTIVES}

We propose the following objectives:

\subsection{General Objectives}

The main objective is to create a modular piece, with which all types of vertical walls can be built inside a building, following a basic assembly scheme and using the new technologies offered by $3 D$ printing.

As is known, the current ceramic bricks meet the expectations related to the functions for which they were designed, but we, in this research, want to add new features, creating printed thermoplastic modular pieces, hereinafter PTMP parts, adapting thus, to new technologies and bringing them closer to the field of construction.
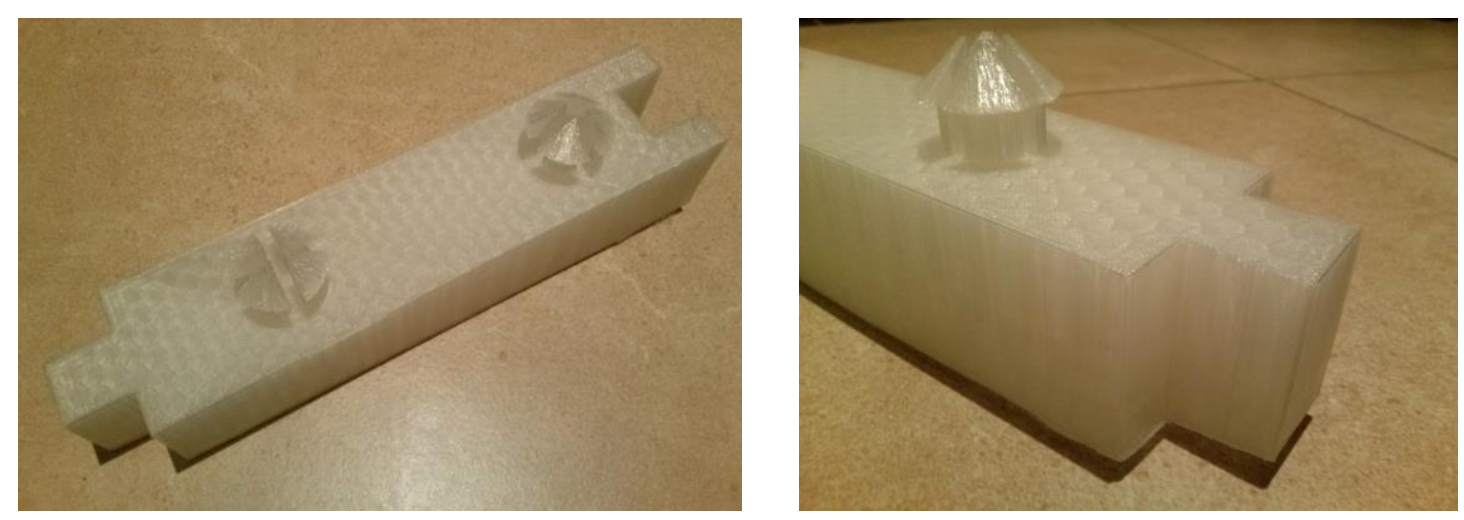

Figure 1. Pieces P.T.M.P. PHOTO OF AUTHOR.

Said modules are equivalent in dimensions to the set of four bricks in face façade, and will be printed in HIPS material almost entirely, with the exception of a vertical and horizontal FILAFLEX membrane, which corresponds to the sealing of joints.

As for the method of assembly, it is done by tongue and groove joints in the vertical joints and by means of staples in the horizontal joints.

By means of this method of union, and by the arrangement of the lower holes of the pieces, the installation can be carried out either in "quincunx" or "kills together", to guarantee the stability of the assembly. 


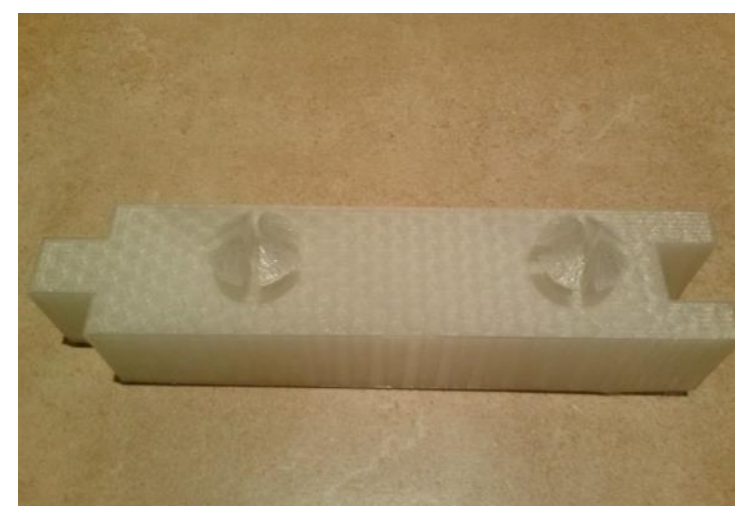

Figure 2. Pieces P.T.M.P. PHOTO OF AUTHOR.

Due to the characteristics of FFD printing, we can print any piece at any time during the construction process, since one of the advantages of $3 \mathrm{D}$ printing is the possibility of designing and printing pieces on site.

In the detailed study of the piece, we have designed interior cells that, not only give stability to the piece, but also make it lighter, being able to create modules of greater dimensions and contribute to the speed of execution of the system. In addition, these cells give thermal and acoustic insulating characteristics that improve the properties of existing bricks.

Once the piece has been designed and printed, laboratory tests are carried out, both for bricks and plastics, and the results are compared with those of a ceramic brick in use.

We emphasize, among others, the different tests that are produced in ceramic pieces.

- Dimensions.

- Flatness of faces.

- Face parallelism.

- Geometry and form.

- Apparent density.

- Absolute density.

- Compression resistance.

- Thermal resistance.

- Ice / thaw resistance.

- Water absorption.

- Suction.

- Moisture expansion.

- Content of soluble salts.

- Reaction to fire.

- $\quad$ Adherence.

Once the physical and mechanical characteristics of the pieces are known, we will proceed to the adjudication of new uses, both in the field of building, and in the field of construction in general.

In addition, we have the possibility of manufacturing new modular elements, taking advantage of new technologies and thus improve the construction processes, as we will mention later. 


\subsection{Specific Objectives.}

Regarding the specific objectives, and to carry out our research, we will clearly define the minimum characteristics that a piece must meet. P.T.M.P.

\section{- Geometry:}

It is, as we have already mentioned, a piece of dimensions $49 \times 11,5 \times 11 \mathrm{cms}$. (rope $\times$ blight $\mathrm{x}$ thickness), equivalent to the arrangement of four bricks in face façade, plus the proportional part of the joints; with staples divided into rooms for horizontal joints and tongue and groove joints in vertical joints; and composed of hexagonal interior cells of $1 \mathrm{~cm}$ side.

\section{- Composition:}

HIPS material at $89.05 \%$ of the piece and FILAFLEX at $10.95 \%$. Each of the materials provides specific characteristics to the piece.

\section{- Characteristics:}

The piece must meet all the requirements of the UNE EN 771 and UNE EN 772 standards. [1] [2]

\section{REGULATIONS IN FORCE}

\section{CTN 136 - CERAMIC MATERIALS OF COOKED CLAY FOR CONSTRUCTION}

Pieces and ceramic clay products for construction such as: bricks, blocks, tiles, vaults and boards, in their aspects of definitions, classification, specifications and test methods.

\section{International Standard}

CEN / TC 125 / WG 1 / TG 1 Masonry. Masonry products. Ceramic products

CEN / TC 125 / WG 9 Masonry. Bovedillas of clay clay.

CEN / TC 128 / SC 3 Discontinuous installation products for roofing and wall covering. Baked clay tiles

CEN / TC 178 / WG 3 Units for pavements and curbs. Ceramic products

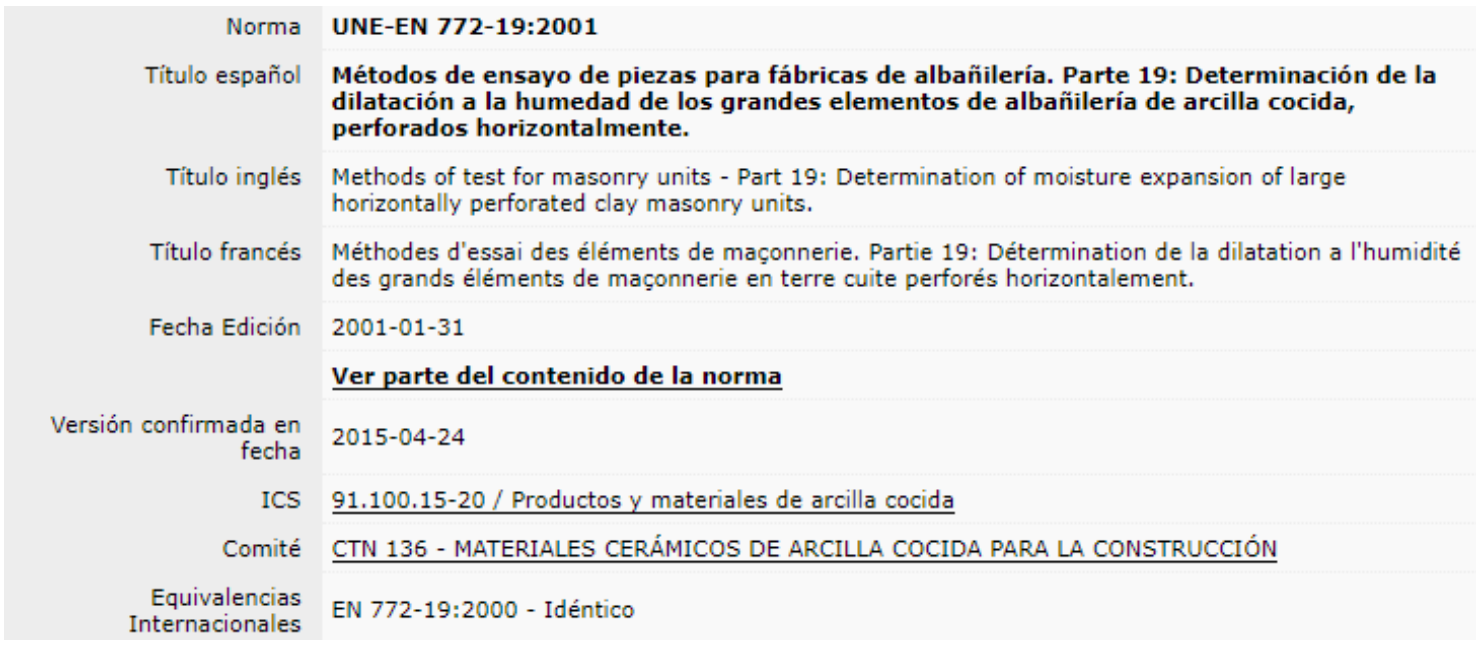

Figure 2. Spanish Association for Standardization and Certification.

Among the main characteristics that our pieces must fulfill, we mention the following:

Resistance to the weather and high temperatures.

Self-supporting.

Machin able.

No ox disable.

Sustainable.

Recyclable. 
Thermal insulation.

Electrical insulators.

Acoustic insulators.

Great resistance to corrosion and the effects of erosion.

High resistance to almost all chemical agents.

Little resistance to stress efforts.

Little elasticity.

\section{Applications:}

The main use of these pieces is for the realization of vertical walls, especially facades, although for its properties, it can be used for interior partition walls, partitions, walls below ground, as well as pigeon walls or roofing.

Sustainability:

Collaborate with sustainable development in the field of building; If a plastic material takes 500 years to finish biodegrading and we transfer it to a home, we not only manage to eliminate waste from the planet, but we also extend the useful life of the building to 500 years. [3]

It is very important to create sustainable and ecological homes, these pieces not only contribute to energy savings due to their thermal insulation capacity, but they are completely reusable and do not cause any type of demolition in their demolition. [4]

\section{BACKGROUND-STATE OF ART}

There are, throughout history, several attempts to make pieces, substitutes for conventional bricks, made with plastic materials, especially in underdeveloped countries, both for the scarce material resources and the need to recycle existing materials.

One example is the houses made with recycled plastic bricks by the architect Óscar Méndez, cofounder of Conceptos Plásticos, which manufactures homes for people with few resources. [8]

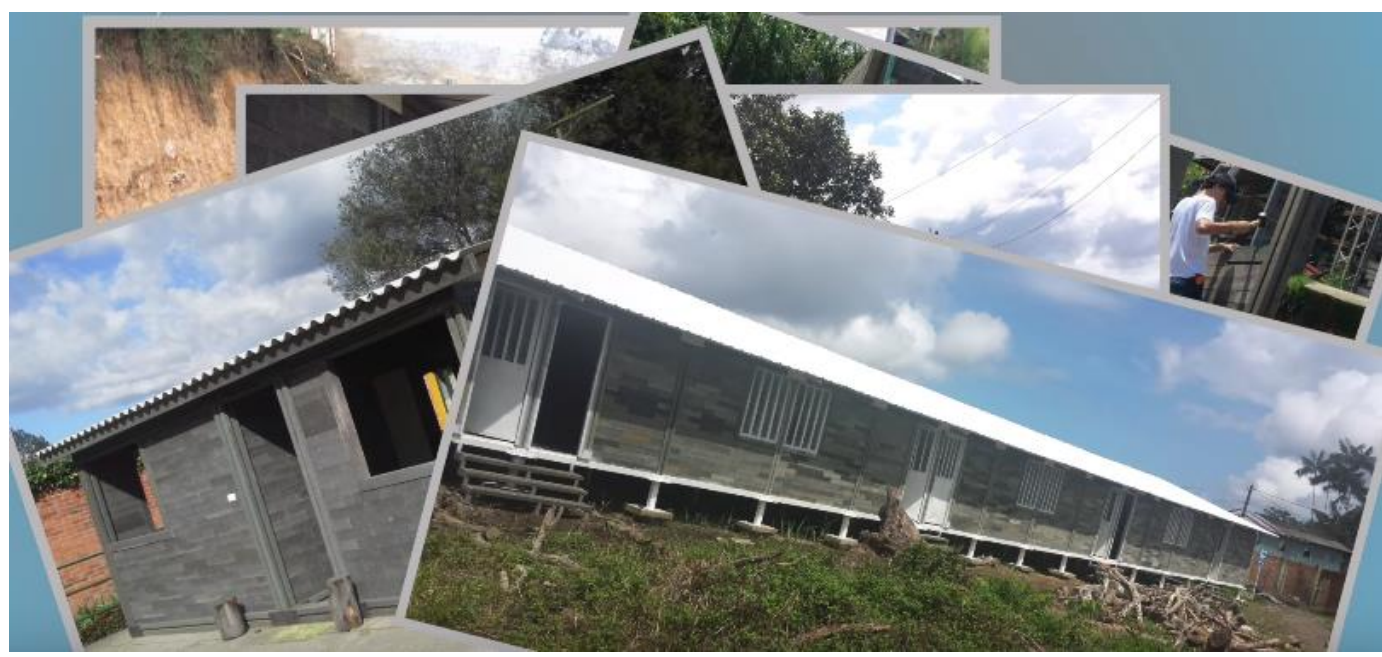

Figure 2. Óscar Méndez. ELEMPLEO.

On the contrary, in Eastern countries, which achieve the greatest technological progress, we can know the most advanced 3D printing techniques, which are capable of printing entire buildings in a few hours, as is the case of the Chinese company WinSun, which he had been able to build, through 3D 
printing, ten houses in Shanghai, each with $200 \mathrm{~m} 2$, at the cost of 30,000 yuan (about $\$ 4,800$ ) and thanks to the use of a huge printer.

In any case, we have not found data on research related to our prototype, except for the "3D-printed ceramic brick" that, after participating in a six-week residency program at the European Ceramic Work Center. His research focused on the process of creating "ceramics on the scale of architecture", including the use of it to create interlaced and stacked bricks (honeycomb bricks). The 3D printing technique is used, but the material is ceramic.

\section{PROPOSED METHODOLOGY}

To elaborate the methodology of this investigation, we will carry out the following guidelines:

- Design of the piece, dimensions and joining systems.

- $\quad$ Study of the physical and mechanical characteristics.

- $\quad$ Choice of the materials used and the guidelines for the correct printing.

- $\quad$ Print the necessary parts to carry out the tests of the regulations.

- $\quad$ Perform laboratory tests.

- Taking data of the results obtained.

- Analysis of the data obtained.

- Comparison of results and requirements of the standard.

- Improve initial conditions.

- $\quad$ Perform final machining tests.

- $\quad$ Propose new uses and new construction elements.

- Posing future lines of research.

- Last conclusions.

\section{STUDY DEVELOPMENT}

It is necessary to make a detailed study of the tests established by the regulations on similar pieces, as well as to foresee the material means necessary to carry out said tests.

In the event that the prototype is printed at scale, the relationship between the results of the tests and the requirements of the regulations will be sought.

As mentioned above, HIPS is used as a support element or support material for the printing of other objects, and is soluble in limonene.

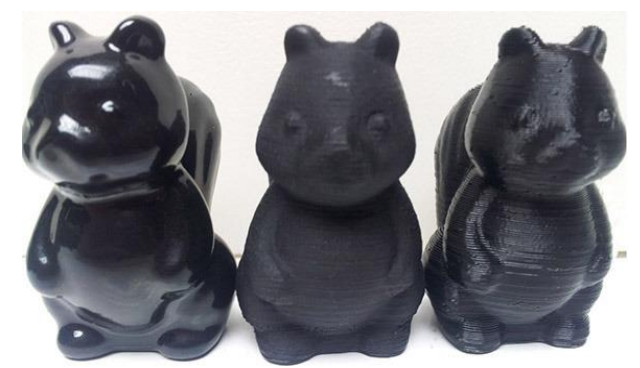

Figure 2. Manuel Lòpez Michelone. BRILLIANT FINISH FOR 3D PIECES.

All the necessary tests will be carried out to see how the piece acts, when it is subjected to the boiling limonen vapor exposure for its correct post-processing and final finishing. [9] 


\section{COMPARATIVE STUDY}

The data will be taken from the trials using the tables and graphs needed to be able to compare the results in a comprehensive, orderly and concise manner.

These data will be compared with those that appear in the regulations, and the difference between both data will be assessed, both in numerical index and in percentage, in order to arrive at some correct conclusions.

The method used for the analysis of results is inspired by the data of the digital electoral Atlas 2005 . Results 1999-2003, Electoral Institute of the Federal District, Mexico. [10]

\section{CONCLUSIONS. RESULTS.}

In this paper we discussed the different teaching methods in which we are moving right now. We have analyzed the methodologies used in the teaching with computers, BIM methodologies, and 3D printer.

These methodologies aims to improve coordination of the project, work efficiency, process of design and graphics, time savings, upgrade the project in real time, the documentation generated and its management, presentations and many points that always helps to have the project updated and coordinated.

It has been analyzed as when disciplines are taught by computer it is important to be careful that the student not only understands the program that uses, but also the philosophy of the system and creates a critical spirit of the means employed.

You have to teach students to analyze the works that exist in that environment, so that it can create a certain conscience of work to develop.

This selection criterion is more important than the fact to teach an application of a particular program, because that can be learned by many means yet that the professional knows what he wants to express and do it with the appropriate means is the most important.

This fact requires on changing the mindset and understands the new philosophy of computer design and optimizes the use of orders for greater accuracy and speed in the generation of our paths. But one must know how to distance from the medium.

Personally I like to draw, and the same happens to most architects, engineers and designers I know. It helps us to think and is a mean of expression among professionals. The hand drawing is transportable and it can be drawn anywhere. After all developing a concept only requires pencil, paper and a professional. When I'm drawing I do not want any interruptions or any error message appearing before me on the screen.

Drawing is how you learn Architecture, but only when drawing is not treated as a mechanical convection approach but as a process of thinking-acting. Using space symbols that imitate invent and confront, by taking in consideration, perceiving and performing them. To do this we must understand the methodology used, specified in each mean, since it is difficult to reach mastery in something without being aware of the sequence of acts performed. But the mean is only the instrument to achieve the end, is not the aim of the work. It should be given more importance to education than technology. With the 3D printers we can not only present or projects we can investigate in new materials.

We are witnessing the beginning of a great revolution in the field of learning. Since the invention of printing there hasn't been a technological breakthrough of such importance for the education system, such as distance learning over the Internet. It is evident that the current situation of distance learning is not definitive. Current means are relatively primary compared with those which will exist in a few years.

We have much to learn about the learning process and, in particular, with the use of new technologies. Therefore an analysis of the educational system is necessary to realize if our current strategies, even the most advanced, and techniques are most suitable for the future society. We must be prepared for the changes that the society demands of us. This will create an appropriate professional for the demands of social future.

I conclude by encouraging them to develop their own ideas for the future of the teaching of graphical expression of our universities. It is important in an epoch of great changes that we have clear our 
goals. We cannot work in stages, reacting hastily to each development when it appears. On the contrary we have to be clear about the purposes for then choose the most appropriate means. The decisions made in the next few years will affect our education system in several decades.

Thanks to new technologies, we have the possibility to print any piece, at any time, within the construction process.

Due to the properties of HIPS and FILAFLEX, the pieces P.T.M.P., acquire extra properties with respect to traditional ceramic brick.

With the new design of the pieces P.T.M.P. we manage to speed up constructive processes and save costs. Since it does not need specialized personnel for its placement, nor for its printing.

Depending on the data obtained in the compression resistance tests, we can use the bricks P.T.M.P. for the realization of load-bearing walls, thus discarding the execution of structural vertical elements.

The possibility of placing them to bone, eliminates a game of execution and makes the construction process easier, with what that entails.

It is an ecological and sustainable product.

Extends the life of the building $500 \%$.

Low cost for construction in large quantity.

The pieces P.T.M.P. they are called foolproof [1], they do not admit error in the placement among them, except for setting out errors.

With this information we can propose a series of hypotheses based on data that serve as the basis to start an investigation:

The pieces P.T.M.P. They may be:

- More ecological and sustainable.

- More resistant

- Faster execution.

- Does not need bonding mortar.

- $\quad$ Earthquake resistant.

- Thermoacoustic.

- Incrementables in height.

- Lower cost of production on a large scale.

- Less manufacturing energy is used.

- Durability of the home.

- $\quad$ No specialized labor required.

- $\quad$ Streamline construction processes.

- $\quad$ Quality of the material.

- Raincoat.

- $\quad$ Structurally stable.

- $\quad$ Printing in different colors, even translucent.

- Less transportation cost.

These hypotheses are pending of the results of the laboratory tests, and their subsequent comparative analysis with a traditional brick.

In short, using the means offered by the new technologies of 3D printing, and recycling a product such as plastic, which is so polluting by the number of years it takes to biodegrade, we can create a brick prototype, which behaves much better in almost all aspects than the traditional ceramic brick, contributing to improve the environment, the constructive economy and sustainability in the building. 


\section{REFERENCES}

[1] UNE-EN 771-1: 2011. Parts specifications for masonry factory. Part 1: Pieces of baked clay. (2011).

[2] UNE-EN 772-1: 2011. Test methods for masonry pieces. Part 1: Determination of compressive strength. (20011).

[3] Gaggino, R. (2009). Journal/Conference Article Title "Bricks and plates prefabricated with recycled plastics suitable for self-construction”. INVI Magazine, 23 (63).

[4] Althaus, D. (2009). Journal/Conference Article Title "Build ecologically INVI Magazine", 6 (12).

[5] Román Torre, LABORAL Online Article Title CENTER OF ART AND INDUSTRIAL CREATION, 3D Printing, December 28, 2018.

Retrieved from http://www.laboralcentrodearte.org/en/files/2013/bloglaboral/breve-introduccion-ala-impresion-3d

[6] Susana Sánchez, Online Article Title 3DNATIVES, FDM or molded deposition modeling, January 01, 2018.

Retrieved from https://www.3dnatives.com/en/modelado-por-deposicion-fundida29072015/

[7] José Bernabé, Online Article Title IMPRESORAS 3D, The definitive guide on the different filaments for 3D printers, January 04, 2018.

Retrieved from https://impresoras3d.com/blogs/noticias/108879559-la-guia-definitiva-sobre-losdistintos-filamentos-para-impresoras-3d.

[8] Óscar Méndez. ELEMPLEO, Online Article Title The architect who creates Lego houses, January 03, 2018.

Retrieved from https://www.youtube.com/watch?v=uu0pNCkSNNc

[9] M. Scian, Online Article Title PRINT A LOT, HIPS as support material, January 06, 2018.

Retrieved from http://www.printalot.com.ar/tutoriales/hips-como-material-de-soporte/

[10] César A. Ruiz. Online Article Title SLIDESHARE. Statistics, percentages, proportions and reasons, January 06, 2018

Retrieved from https://es.slideshare.net/carc1975/210-3486ydg 